\title{
Health benefits of barley for diabetes
}

\author{
Emmanuel Idehen, Weixin Wang and Shengmin Sang*
}

\begin{abstract}
Laboratory for Functional Foods and Human Health, Center for Excellence in Post-Harvest Technologies, North Carolina Agricultural and Technical State University, North Carolina Research Campus, 500 Laureate Way, Kannapolis, North Carolina 28081, United States ${ }^{*}$ Corresponding author: Shengmin Sang, Laboratory for Functional Foods and Human Health, Center for Excellence in Post-Harvest Technologies, North Carolina Agricultural and Technical State University, North Carolina Research Campus, 500 Laureate Way, Kannapolis, North Carolina 28081, United States. Tel: 704-250-5710; Fax: 704-250-5709; E-mail: ssang@ncat.edu or shengminsang@yahoo.com DOI: $10.31665 /$ JFB.2020.12246
\end{abstract}

Received: December 06, 2020; Revised received \& accepted: December 22, 2020

Abbreviations: AMPK, 5' AMP-activated protein kinase; AUC, Area under the curve; DF, Dietary Fiber; GI, Glycemic index; GLP-1, Glucagon-like peptide-1; GLUT2, Glucose transporter 2; GPR41/43, G-protein coupled receptor 41/43; GR, glycemic response; HBG, High $\beta$-glucan; HepG2, a human liver cancer cell line; HFC, High fiber cellulose; HNF1, the hepatocyte nuclear factor 1; HNF3, the hepatocyte nuclear factor 3; IL-6, interleukin 6; NA/STZ, nicotinamide/streptozotocin; PPAR $\gamma$, Peroxisome proliferator-activated receptor gamma; PYY, Peptide YY; SCFAs, Short chain fatty acids; SREBP1c, Sterol regulatory element-binding protein 1c; T2D, Type 2 diabetes; TNF- $\alpha$, Tumor necrosis factor; WG, whole grain

Citation: Idehen, E., Wang, W., and Sang, S. (2020). Health benefits of barley for diabetes. J. Food Bioact. 12: 76-86.

\begin{abstract}
Type 2 diabetes (T2D) is one of the most prevalent metabolic disorders in the United States. Increased blood glucose levels and improper crucial metabolism ensuing from insulin action, insulin secretion defect, or both are characteristics of this disease. The risk of developing T2D is associated with many factors, including obesity, race, inactivity, and genetics. Increased whole-grain (WG) consumption has been reported to lower the risk of obesity and T2D. Among WGs, barley shows a comparative advantage in its fiber content, especially the soluble fiber, beta-glucan ( $\beta$-glucan), an active component credited for this benefit. Barley also contains important phytochemicals, mostly intertwined with its fiber, reported to offer glycemic response benefits. The mechanism by which barley exerts these changes in glycemic response is not entirely understood. However, the physical properties of barley fiber, the function of microbial metabolites of fiber, short chain fatty acids, and the beneficial effects of its phytochemicals through multiple pathways have all been reported as the potential mechanisms for its antidiabetic effects. This review summarizes recent studies concerning the health-promoting benefit of barley in preventing and moderating the risk factors associated with diabetes and the potential underlying mechanisms.
\end{abstract}

Keywords: Barley; Diabetes; B-Glucan; Short Chain Fatty Acids; Phytochemicals.

\section{Introduction}

Diabetes is the seventh leading cause of death in the United States, with a reported two to three-fold increase in mortality and a decreased life expectancy of up to eight years (Gæde et al., 2016; Li et al., 2020). In 2018, the US Center for Disease Control and Prevention reported that 34.2 million Americans and $10.5 \%$ of the US population were diagnosed with diabetes, buttressing this disease's gravity (CDC 2020). Most reported cases of diabetes are type 2 diabetes (T2D) (90\% of all cases) (Bullard et al., 2018; Holman et al., 2015), which results from a developed resistance to insulin or the pancreas inability to produce enough insulin (Critchley et al., 2018; Redondo et al., 2020). Although the precise underlying cause of T2D is not entirely understood, a combination of genetic susceptibility, environmental factors, and consumption of high glycemic index diets appears to be significant risk factors for the occurrence of diabetes (Esposito et al., 2019; Li et al., 2020; Sado et al., 2016).

Postprandial glucose control is a crucial strategy for managing T2D, with diet therapy often the first-line approach for this con- 
trol (Evert et al., 2019). Nutrition therapists and health practitioners recommend consuming foods with a slow absorption rate and low glycemic index (GI) as a strategy for modulating glycemic response (GR) in individuals with $\mathrm{T} 2 \mathrm{D}$, with characteristics of efficiency and cost-effectiveness (Eleazu 2016; Fujiwara et al., 2017; Kavitha and Parameshwari 2019; Wolever 2006). Furthermore, since the amount and type of ingested carbohydrate is usually the primary factor determining postprandial glycemic response, functional foods with low GI and slow glucose absorption rates are now being developed to manage obesity and diabetes. Consequently, the evolving understanding of WG's importance in diets has led to an interest in its use as a functional food in diabetes control.

Whole grains (WGs) are generally low GI foods with an established metabolic link between their consumption and reduced risk of T2D and obesity. Results from extensive prospective cohort studies unequivocally indicate that a high intake of WG products (in most studies, $>30-40 \mathrm{~g} / \mathrm{d}$ ) rich in fiber may help reduce insulin resistance and the risk of developing T2D by up to $20-30 \%$ (Weickert and Pfeiffer 2018). Due to the aforementioned benefit, the Health and Human Services and the United States Department of Agriculture (USDA) released guidelines that recommend and assert that consuming about 3 to 8 ounce-equivalents of WG each day may help reduce the risk of chronic diseases, including T2D and obesity (Croke 2016; DeSalvo 2016). Epidemiological evidence has also indicated that individuals who consume an average of two-to-three servings (60-90 g/day) of WGs daily may experience a $21-32 \%$ decrease in the prevalence of T2D compared to those who hardly or never consume WGs (Della Pepa et al., 2018). Probable candidates for WG's efficacy in disease prevention and control are: enhanced insulin sensitivity, modulation of inflammatory markers, and direct and indirect influences on the gut microbiota (Aydin et al., 2018; Kim et al., 2017; Malin et al., 2018).

Among WG's, there appears to be the potential for more utilization of barley in functional foods as part of a low GI diet and an additional strategy for preventing diabetes and obesity. This is due to barley's classification as not just a low GI food but its high fiber content relative to other WGs and its unique phytochemical configuration with implications for oxidative stress and inflammation control; both risk factors lead to diabetes. The international table for GI and glycemic load values classifies barley as the WG with the lowest GI (Atkinson et al., 2008). This classification is noteworthy as the consumption of a high-GI diet is associated with an increased risk of developing T2D, while a low-GI diet may decrease the need for anti-hyperglycemic medications. Regarding barley's ability to moderate diabetes, several well designed, extensive, prospective cohort studies have attributed the anti-diabetic benefit of barley mainly to the effect of the soluble fiber, $\beta$-glucan (Association 2017). Interestingly, except for oat, barley is the only WG that contains $\beta$-glucan in a significant amount. Depending on the variety, genetics, and environmental factors, the quantity of $\beta$-glucan in barley may exceed that of oat. A study by Havrlentova et al., which examined the $\beta$-glucan content of different spring barley and oat genotypes, found $\beta$-glucan at average levels of $41.6 \mathrm{~g} / \mathrm{kg}$ in barley and $34.9 \mathrm{~g} / \mathrm{kg}$ in oat. In a similar experiment, Lee et al. compared the $\beta$-glucan content of nine barley and ten oat genotypes grown consecutively, recording slightly higher $\beta$-glucan content for barley $52.3 \mathrm{~g} / \mathrm{kg}$ than Oat $51.0 \mathrm{~g} / \mathrm{kg}$ (Lee et al., 1997). Aside from $\beta$-glucan's presence in barley in substantial quantity, barley is equally more economical to cultivate due to its winter-hardy, drought-resistant, and early maturing nature, which portends well for its widespread use as a dietary agent in the prevention of T2D and obesity. Thus, the present review aims to summarize the available evidence derived from epidemiological studies, intervention trials, and rodent studies on the possible protective effects of barley on $\mathrm{T} 2 \mathrm{D}$, and the reported mechanisms from its unique components (fiber, its microbial metabolites, and phytochemicals).

\section{Anti-diabetic effects of barley: evidence from human studies}

WG barley and isolated barley $\beta$-glucan have been broadly studied for their ability to impact diabetic markers among diabetic, obese or overweight, mildly diabetic, and healthy individuals, with varying degrees of success (Chillo et al., 2011; Higa et al., 2019; Liu et al., 2015; Tosh 2013). Most of these studies also enriched or incorporated WG barley and $\beta$-glucan into various food like bread, porridge, tortillas, and pasta while evaluating their ability to exert glycemic control. Generally, the results of these clinical trials and experimental studies have shown evidence in favor of lowering postprandial glycemic response. However, while most studies have reported a significantly reduced glycemic response, some studies, especially those which incorporated barley and barley $\beta$-glucan into different food, failed to find the same effect due to variations in the food's physical properties, such as molecular weight and viscosity (Smith et al., 2008; Thondre and Henry 2011). All in all, it appears that clinical trials on barley and glycemic response in humans show evidence in favor of a lowered postprandial glycemic response.

AbuMweis and colleagues conducted a meta-analysis that explored whether changes in glucose response after consuming barley products were enough to be considered physiological relevant. This meta-analysis concluded that barley and barley $\beta$-glucan lowered postprandial glycemic response in magnitudes large enough to be regarded as a physiological change (AbuMweis et al., 2016). The results showed that barley and barley $\beta$-glucan significantly reduced glucose area under the curve (AUC) by $-34.4 \mathrm{~min} \times \mathrm{mmol} / \mathrm{L}$, while the glycemic index was considerably lowered by $(-24.3)$. AUC for insulin was also reduced by $2,577 \mathrm{~min} \times \mathrm{pmol} / \mathrm{L}$, while insulin index was reduced by -33.8 . A 2020 review by Tosh and her team, who scrutinized 34 studies on the influence of $\beta$-glucan, extracted from barley and oat, on postprandial blood glucose concentration, found that $4 \mathrm{~g}$ of $\beta$-glucan substantially reduced glycemic response, especially for meals containing barley (Tosh and Bordenave 2020). An observation study by Aldughpassi et al., which examined the impact of nine barley cultivars on participants' blood glucose levels, found that all barley cultivars significantly altered all ten healthy participants' GR. All barley test meals provoked significantly lower glycemic reactions with a GI range of 21-40 (Aldughpassi et al., 2012). Tosh and colleagues conducted a cohort study investigating the effect barley products high in soluble dietary fiber (DF) have on glycemic and insulin response compared to high in insoluble DF products. This study found that there was more noticeable decisive protective action against diabetes and obesity for soluble DF than insoluble fiber products. The authors of this study concluded that the processing procedures that result in more $\beta$-glucan content presented the most astounding benefit in GR (Tosh 2013). In an observational study involving ten participants, Thondre et al. investigated the impact of barley fiber on glycemic and insulin response in participants who consumed barley meals prepared from two different barley types $(16 \mathrm{~g} / 100 \mathrm{~g}$ and $10 \mathrm{~g} / 100 \mathrm{~g}$ fiber content). Irrespective of the serving sizes (equivalent to either 25 or $50 \mathrm{~g}$ available carbohydrate) and fiber content, both barley meals significantly lowered GR when compared to reference glucose $(\mathrm{P}<0.05)$. Interestingly, there was no difference in the GR to both barley grains regardless of the difference in total fiber content or serving size. However, 
both barley types' soluble fiber content were similar, suggesting a more pronounced impact on glycemic and insulin response from different soluble fiber content than total fiber content (Thondre et al., 2012). This conclusion was supported by Bourdon et al. who investigated insulin and glucose responses in eleven healthy men who consumed two test meals containing different $\beta$-glucan contents $(5.0 \mathrm{~g}$ and $15.7 \mathrm{~g})$. Glucose was more slowly absorbed into the blood from the higher $\beta$-glucan enriched meals than the low fiber meals, suggesting that the difference in $\beta$-glucan plays a significant role in diabetes control (Bourdon et al., 1999). A randomized, single-blind study, which assessed the effect of barley $\beta$-glucan with different molecular weight on GR in fifteen healthy subjects established a relationship between $\beta$-glucan's molecular weight and improvement in glycemic response (Thondre et al., 2013). The impact of different $\beta$-glucan's concentration on GR was examined by Chillo et al., who designed a study that measured the GR of nine healthy subjects who consumed spaghetti meals enriched with different amounts of barley $\beta$-glucan $(0 \%, 2 \%, 4 \%$, $6 \%, 8 \%$, and $10 \%$ ). Measured blood glucose levels, $120 \mathrm{~min}-$ utes after consuming different $\beta$-glucan enriched spaghetti diets, showed a GI decrease with increasing $\beta$-glucan concentration. Notably, the GI of $10 \% \beta$-glucan spaghetti was $54 \%$ lower $(\mathrm{P}<0.02$; $\mathrm{GI}=29)$ than that of the control $(\mathrm{GI}=64)$, making this product a markedly low-GI food, for semolina spaghetti and control spaghetti, respectively (Chillo et al., 2011). Ames et al. also confirmed barley $\beta$-glucan's positive impact on improving insulin response in a double-blind, randomized, and controlled study (Ames et al., 2015). where twelve healthy adults consumed varying amounts of barley $\beta$-glucan enriched meals (low: $4.5 \mathrm{~g}$, medium: $7.8 \mathrm{~g}$, and high: $11.6 \mathrm{~g}$ ). There was a $39 \%$ lower insulin release after high $\beta$-glucan treatment than the medium $\beta$-glucan treatment, which had a 33\% lower insulin response than the low- $\beta$-glucan treatment. Remarkably, from this study, it was observed that amylose and insoluble fiber did not alter postprandial glucose and insulin levels in blood samples examined. Additionally, while all barley meals elicited lower postprandial glucose response, it was observed that increasing the barley $\beta$-glucan content in the tortillas meals improved glucose response the most. This finding suggests a possible dose-effect of barley and barley $\beta$-glucan in insulin and GR. The authors concluded that any benefit of increasing amylose content might be masked by the effects of $\beta$-glucan in foods that contain barley (Ames et al., 2015).

Barley fiber's impact on GR has also been compared to other whole grains, showing better moderating benefits from barley. Behall and colleagues compared the effect of barley and oat on glucose and insulin response in a Latin square designed study. In this study, ten women with a body mass index of 30 consumed glucose ( $1 \mathrm{~g} / \mathrm{kg}$ body weight) and different test meals ( $1 \mathrm{~g}$ carbohydrate/ $\mathrm{kg}$ body weight; $2 / 3$ of the carbohydrate from oat flour, oatmeal, barley flour, or barley flakes and $1 / 3$ from pudding) after consuming controlled diets for two days. Glucose AUCs after test meals compared with AUCs after glucose consumption showed reductions after both oat $(29-36 \%)$ and barley $(59-65 \%)(p<0.002)$ meals. However, insulin AUCs after test meals compared with glucose AUCs were significantly reduced only by barley (44-56\%) (p $<0.005$ ) (Behall et al., 2005). Casiraghi et al. also compared the postprandial glucose and insulin response of crackers or cookies made from barley and whole wheat flour or flour enriched with barley $\beta$-glucan. While barley products provided 12 grams of dietary fiber with 3.5 grams of $\beta$-glucan per portion, the wholewheat products provided 14 grams of dietary fiber with negligible $\beta$-glucan. The results showed that GI was reduced by 8.5 to 15.2 GI units per gram of added $\beta$-glucan for the crackers and cookies, respectively (Casiraghi et al., 2006).
Remarkably, barley may not only have a beneficial effect on the glycemic response after a meal in which it is consumed but may also impact insulin responses after succeeding meals. Nilsson et al. studied the impact of barley on GR after subsequent meals in twelve healthy subjects (Nilsson et al., 2008). Results of this study revealed that barley kernel breakfasts lowered blood glucose at breakfast and the next lunch. The cumulative postprandial blood glucose incremental AUC for breakfast, lunch, and dinner were lower than white-wheat bread $(\mathrm{P}<0.05)$. The postprandial blood glucose incremental AUC for lunch positively correlated with breakfast $(r=0.30, P<0.05)$. The evening meal of barley kernel also resulted in lower postprandial blood glucose incremental areas under the curve $(\mathrm{P}<0.05)$ after a subsequent breakfast compared with the control white-wheat bread (Nilsson et al., 2008). This finding was supported by Liljeberg et al. (Liljeberg et al., 1999), who examined the extent to which postprandial glycemic response can be modulated by the GI of previous meals in healthy individuals. Test breakfasts containing four types of high-amylose barley bread, with a GI between sixty and ninety-nine, were evaluated using white wheat bread as the control breakfast. Barley-bread breakfast with the lowest GI resulted in lower glucose levels at 30 and 70 minutes after lunch, compared to the white wheat bread breakfast (Liljeberg et al., 1999).

The impact of barley on glycemic and insulin response has also been examined in intervention studies involving diabetic and mildly diabetic or obese subjects. Azam et al. investigated the effect of barley on postprandial blood glucose response in 20 diabetics subjects (Azam et al., 2019). Subjects were subdivided into two groups, with ten acting as a control group while the other ten formed the experimental group that received a $100 \mathrm{~g}$ barley diet for four weeks. Each subject's blood glucose level was checked at both fasting and after ninety minutes from barley diet consumption. Results showed a significant reduction in blood sugar levels after barley consumption (Azam et al., 2019). A similar intervention study involving 109 T2D subjects who consumed meals enriched with barley reported that glucose and insulin response levels were reduced to extents where patients on oral hypoglycemic treatments were able to discontinue their treatment and still maintain reasonable metabolic control (Hinata et al., 2007). Behall et al. also conducted an intervention study involving obese or overweight individuals with mild diabetes who consumed meals enriched with either barley $\beta$-glucan or resistant starch (Behall et al., 2006). In this study, 20 men comprising ten control subjects of normal-weight and ten overweight or obese subjects consumed several resistant starch diets from high-amylose cornstarch and soluble fiber diets containing $\beta$-glucan barley, in both singular and combined meals. The highest $\beta$-glucan level was the most effective in lowering glucose $(\mathrm{P}<0.001)$ and insulin responses $(\mathrm{P}<0.0001)$. Findings from this study indicated that high $\beta$-glucan meals elicited the lowest average glucose $(\mathrm{P}<0.025)$ and insulin $(\mathrm{P}<$ $0.0001)$ levels than meals involving resistant starch. Thus, it was concluded that the acute consumption of barley $\beta$-glucan, but not resistant starch, effectively reduces glucose and insulin responses in mildly insulin-resistant men (Behall et al., 2006). In this same study, the impact of barley $\beta$-glucan and preformed resistant starch were examined to ascertain whether barley $\beta$-glucan and resistant starch independently or synergistically impacted glucose and insulin responses. For this Latin square design study, ten overweight subjects were fed glucose or one of nine muffins containing three levels of resistant starch $(0.1,6.1$, or $11.6 \mathrm{~g} /$ tolerance $)$ and three levels of $\beta$-glucan $(0.1,3.1$, or $5.8 \mathrm{~g} /$ tolerance $)$. Results showed that acute consumption of barley $\beta$-glucan, but not resistant starch, effectively reduces glucose and insulin responses in mildly insulinresistant men. Pick and his colleague also evaluated the long-term 
effects of incorporating waxy hulless barley with $7 \% \beta$-glucan bread in the typical dietary pattern of twelve men with T2D (Pick et al., 1998). In the twenty-four-week study, five randomly chosen subjects ate barley bread products, while others ate the control white bread diet. The mean total dietary fiber intake was $28 \mathrm{~g} / \mathrm{d}$ for the white bread and $39 \mathrm{~g} / \mathrm{d}$ (10 g/d from barley) for barley bread. Measured blood glucose and insulin (8-h profiles) levels at 0,12 , and 24 weeks indicated that incorporation of barley bread products $(5 \mathrm{~g} / \mathrm{d} \beta$-glucan) into the diet significantly improved GR (Pick et al., 1998).

Observation and intervention studies involving healthy, mildly diabetic and diabetic patients indicate that consuming barley or barley products, at least $4 \mathrm{~g} \beta$-glucan, might significantly reduce GR in diabetic individuals. Thus, increasing barley intake may substantially improve glycemic control and minimize oral medication and insulin doses. Besides, with more individuals preferring food products to pharmacologic agents, barley's utilization in diabetic complication alteration is an exciting prospect. Remarkably, a shrunken-endosperm, short awn, waxy starch, hulless barley product with low starch and high fiber content, called Prowash, was found to elicit reduced postprandial glucose levels both in diabetic and normal subjects by similar levels to those observed in diabetic patients treated with alpha-glucosidase treatment (Rendell et al., 2005).

\section{Anti-diabetic effects of barley: evidence from animal studies}

The impact on diabetes moderation by barley and barley $\beta$-glucan has also been examined using animal models, mainly mice. Most of these studies have focused on its impact on fasting glucose and serum insulin levels. Aside from these markers, barley's action on gut microbiota, improvements in gut hormones, leptin levels, insulin-positive cells, and the groups of pancreatic cells, islets of Langerhans are examined as modulating sign. Concerning the interplay between leptin and adiponectin, leptin treatment has been found to correct plasma adiponectin concentration, a protein hormone that impacts glucose regulation (Miyamoto et al., 2018; Shatwan et al., 2013). Most studies also examine the effect of barley on T2D using obese animal models since obesity is a risk factor closely linked to T2D (Garcia-Mazcorro et al., 2018). Although obesity can result from naturally occurring mutations or genetically manipulated animal models, obesity can also be induced by high-fat (HF) feeding. While obesity in humans is hardly caused by a monogenic mutation, in T2D research, monogenic obese animal models are commonly used. The most widely used monogenic models are often defective in leptin signaling since the absence of leptin causes hyperphagia and subsequent obesity. For chemicallyinduced diabetic non-obesity models, the commonly used inducers are streptozotocin (STZ) and alloxan. While the results of most studies examining barley's impact on the glycemic response have been positive, one study (Belobrajdic et al., 2015) failed to find any relationship between barley and diabetes moderation.

Shatwan et al. evaluated the effects of barley flour, crude cinnamon, and their combination on blood glucose, and serum insulin levels in STZ-treated rats (Shatwan et al., 2013). The rats were divided into five groups comprising of a diabetic, nondiabetic, diabetic group fed $5 \%$ cinnamon, diabetic group fed $30 \%$ barley, and diabetic group fed 5\% cinnamon and 30\% barley. Fasting blood glucose and insulin levels were examined after eight weeks. Results showed a significant change in glucose response for all treated diabetic rats compared with the diabetic control group (Shatwan et al., 2013). Li et al. evaluated the anti-diabetic effects of enzymatically isolated insoluble $(73.93 \pm 0.62 \mathrm{~g} / 100 \mathrm{~g})$ and soluble $(84.07 \pm 0.82$ $\mathrm{g} / 100 \mathrm{~g}$ ) barley fiber on HF diet treated rats (Li et al., 2020). Remarkably, the administration of barley insoluble fiber or barley soluble fiber prevented the progress of T2D, reflected by the reduced level of fasting blood glucose compared with the control diabetes group in the second, third, and fourth week of the experiment ( $\mathrm{p}<$ 0.01 ; at fourth week, $p<0.05$ ). Furthermore, serum level of insulin and the values of homeostatic model assessment of insulin resistance were found to be reduced in the barley soluble fiber-treated diabetic rats compared with those in the untreated diabetic rats ( $p$ $<0.01$ ). The increased value of the quantitative insulin sensitivity check index confirmed the effects of barley soluble fiber treatment on insulin sensitivity $(\mathrm{p}<0.01)$ (Li et al., 2020). A similar study involving four weeks old male $\mathrm{C} 57 \mathrm{BL} / 6 \mathrm{~J}$ mice investigated the impact of a $20 \%$ barley flour containing either high $\beta$-glucan (HBG; $2 \% \beta$-glucan) or low $\beta$-glucan (LBG; $0.6 \% \beta$-glucan) diet on HF diet treated mice under conventional and germ-free conditions (Miyamoto et al., 2018). Additionally, these mice were fed either a HF diet with 5\% cellulose (HFC; high fiber cellulose) or 5\% barley $\beta$-glucan (HFB; high fiber $\beta$-glucan). This study showed that plasma glucose levels of HBG-fed mice tended to be lower than those of control mice $(\mathrm{P}=0.087)$. Results indicated that the HBG diet suppressed the elevation of plasma glucose levels and the increase in body fat mass, preventing the HFD-fed mice from becoming obese (Miyamoto et al., 2018). Moreover, the modification of gut microbiota and the increase of SCFAs (especially butyrate) under conventional condition were observed, and the secretion of the gut hormones PYY and GLP-1 increased in HBG-fed mice, these all contributed to improve insulin sensitivity (Miyamoto et al., 2018). The therapeutic effect of malted barley extract on blood glucose and insulin level has also been investigated in genetically diabetic mice. Results from this study also showed a reduction in fasting blood glucose for the group of mice orally administered $62.5 \mathrm{mg} /$ $\mathrm{kg}$ of body weight of malted barley compared to the control group $(\mathrm{P}<0.05)$ (Hong and Jai Maeng 2004). To investigate the mechanism for the effects of barley $\beta$-glucan, Choi et al. fed three groups of male 7-week-old C57BL/6J mice with high-fat diets containing 0,2 , or $4 \%$ of barley $\beta$-glucan for 12 weeks (Choi et al., 2010). The 2 and $4 \% \beta$-glucan groups had significantly lower body weights than the $0 \% \beta$-glucan Group. The $4 \% \beta$-glucan group demonstrated improved glucose tolerance, lower insulin-resistance index, and glucose-dependent insulinotropic levels. Consumption of 2 and $4 \% \beta$-glucan for 12 weeks resulted in 6.4 and $4.5 \%$ reductions in body weight, respectively, compared with $0 \% \beta$-glucan Group $(\mathrm{p}<$ 0.05 ), while no significant differences in food intake between the treatment groups were observed. Performed glucose tolerance tests after eleven weeks of $\beta$-glucan consumption indicated that $4 \%$ of $\beta$-glucan significantly increased the glucose response during 2 -h glucose tolerance tests compared to the $0 \% \beta$-glucan Group. The area under the curve values was significantly reduced in the $2 \%$ and $4 \% \beta$-glucan Group, which indicates enhanced insulin sensitivity. Consumption of $4 \% \beta$-glucan markedly reduced serum insulin compared with $0 \% \beta$-glucan (from $550.1 \pm 65.4$ to $340.1 \pm 43.1$ $\mathrm{pmol} / \mathrm{L}$, respectively), even though insulin content in the pancreas was not significantly different. Consumption of $4 \% \beta$-glucan significantly reduced serum glucose-dependent insulinotropic peptide compared with $0 \% \beta$-glucan (Choi et al., 2010). Brockman's study, which subjected fatty rats to glucose tolerance tests, verified the assumption that barley and its $\beta$-glucans content improves glucose control through better control of postprandial glycemia. At the end of this six-week study involving chronic consumption of whole grain barley flour, rats fed with WG barley flour had a significantly lower glycemic response and improved insulin resistance than the control group (Brockman et al., 2013). 

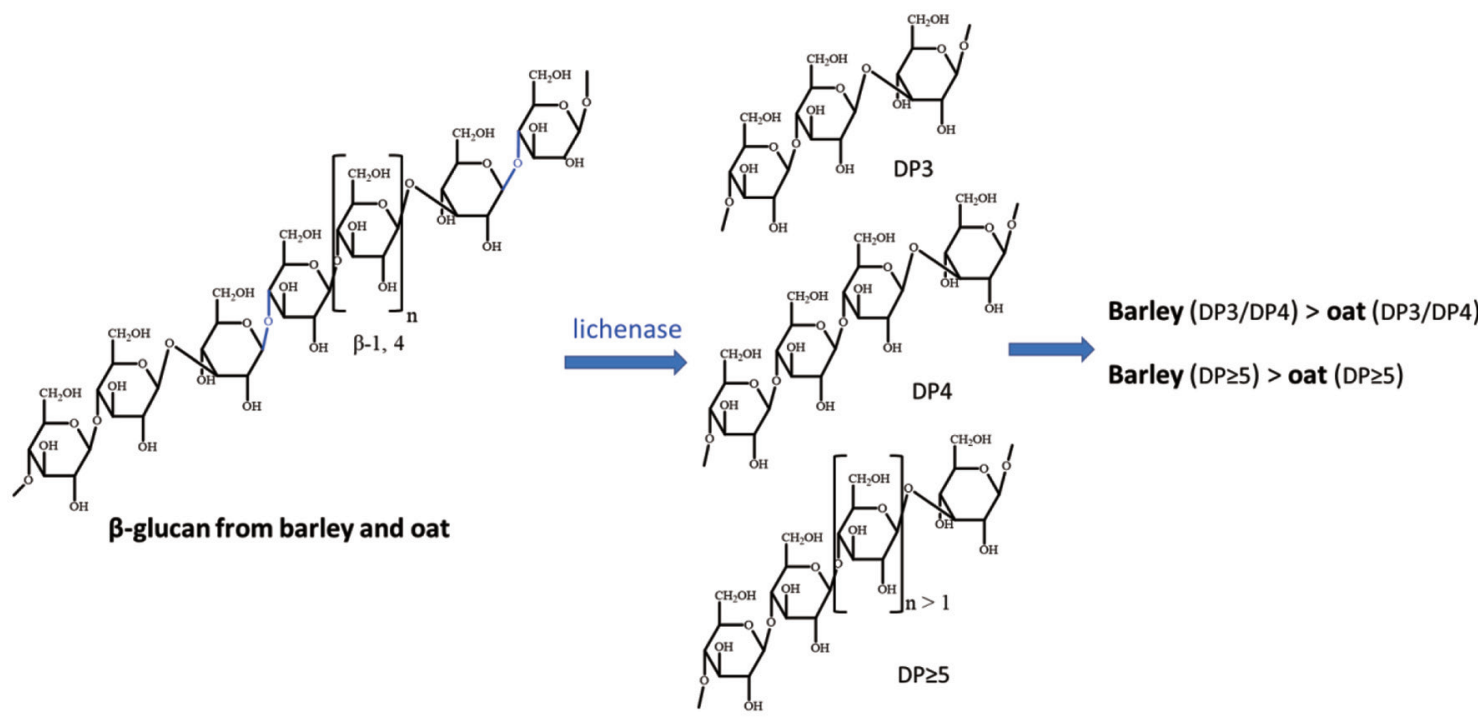

Figure 1. The structures of barley $\beta$-glucan and oat $\beta$-glucan, and their difference.

In contrast to findings showing favorable GR after barley consumption, Belobrajdic et al. sought to test the hypothesis that barley $\beta$-glucan fermentation raises circulating incretin hormone levels and improves glucose control, independent of other grain components. Results from this study found that although WG barley $\beta$-glucan suppressed feed intake and increased cecal fermentation, it did not improve postprandial glucose control or insulin sensitivity in Male Sprague-Dawley rats $(\mathrm{n}=30)$ fed a high-fat diet for six weeks and then randomly allocated to 1 of 3 dietary treatments for two weeks; low (LBG, $0 \% \beta$-glucan) and high (HBG, $3 \% \beta$-glucan) $\beta$-glucan diets contained $25 \% \mathrm{WG}$ barley and similar levels of insoluble dietary fiber (Belobrajdic et al., 2015).

\section{Mechanisms of the anti-diabetic effects of barley}

The beneficial effect of barley on serum insulin, blood glucose, and diabetes moderation is credited to the viscous fiber, $\beta$-glucan. It has been hypothesized that this benefit may be a function of the physical properties, especially the viscous and gel-forming soluble DF component of barley (Bozbulut and Sanlier 2019; Schloermann and Glei 2017). Soluble barley fiber, especially $\beta$-glucan, creates increased viscosity in the gut, slowing down the digestion rate of high glycemic index foods, stomach emptying, and glucose absorption (Bozbulut and Sanlier 2019). Barley $\beta$-glucans might also reduce food digestibility by regulating water availability or altering the microstructure of food products (Brennan 2005). Another advanced idea is that colonic fermentation after a meal of soluble barley fiber may also contribute to subsequent meal improvements in postprandial glycemia. Furthermore, barley $\beta$-glucan may affect serum short-chain fatty acid concentration resulting from colonic fermentation of soluble fibers, which may positively affect glucose metabolism (Kim 2018). Soluble barley fibers may also alter the levels of gut hormones involved in appetite and satiety (Schroeder et al., 2009). Moreover, barley phytochemicals may play an essential role in moderating glycemic response by acting as antiinflammatory and anti-oxidant agents, both risk factors associated with diabetes (Belobrajdic and Bird 2013). Inhibition of amylase and delayed starch hydrolysis, or the reduction in diffusion to the small intestinal microvilli of amylolytic products, may also im- pact glycemic response after a barley treatment. It has also been projected that barley's viscous nature helps develop an absorptive barrier layer through interactions with the mucosa.

\subsection{Physiological effects from fiber}

Barley is an essential source of dietary fiber as it contains about 15-24 g of dietary fiber per $100 \mathrm{~g}$ of WG on a dry weight basis. Fiber composition of different barley varieties ranges from $9 \%$ to greater than $30 \%$, with fiber content present in soluble and insoluble forms and composition correlated with the amount of polymerization (Bai et al., 2019). For blood glucose management, barley's soluble fiber component has been mainly credited for this benefit, especially $\beta$-glucan (Behall et al., 2006). In a 2008 study, Wang et al. reported that high viscose $\beta$-glucan solution extracted from barley exhibited a higher capacity to reduce total blood glucose (Henrion et al., 2019).

Barley $\beta$-glucans are linear polysaccharides linked by $\beta-1,3 / 1,4$ glycosidic bonds with the $\beta-1,4-$ linked glucose chain $(\sim 70 \%)$ interrupted by $\beta-1,3$ linkages $(\sim 30 \%)$ (Goudar et al., 2020; Lazaridou and Biliaderis 2004). The structural difference of barley $\beta$-glucan compared with oat $\beta$-glucan is due to a slight difference in the ratio of the two central oligomer units, trisaccharide unit (DP3) and tetrasaccharide unit (DP4) (Figure 1) (Lazaridou et al., 2004; Mikkelsen et al., 2013), which explains more than $90 \%$ of $\beta$-glucan structures. While the ratio of DP3 to DP4 in barley is 2.8-3.4, that of oat is 2.1-2.4 (Wood 2011). Another structure difference is barley has more $\beta-1,4$ linkages with a degree of polymerization higher than 4 , and longer blocks of up to 14 adjacent exist (Vaikousi et al., 2004; Woodward et al., 1983). These structural features are important to $\beta$-glucan's water solubility, viscosity, and gelation properties. Furthermore, the difference in molecular weight, viscoelasticity, conformational change in a solution, gelling properties, and interaction between other compounds are indicators of barley $\beta$-glucans functionality in food systems and its ability to affect postprandial response.

The positive effects of $\beta$-glucans on blood glucose, insulin response, and diabetic risk factors are well recognized. For example, the European Food Safety Authority approved a health claim for 


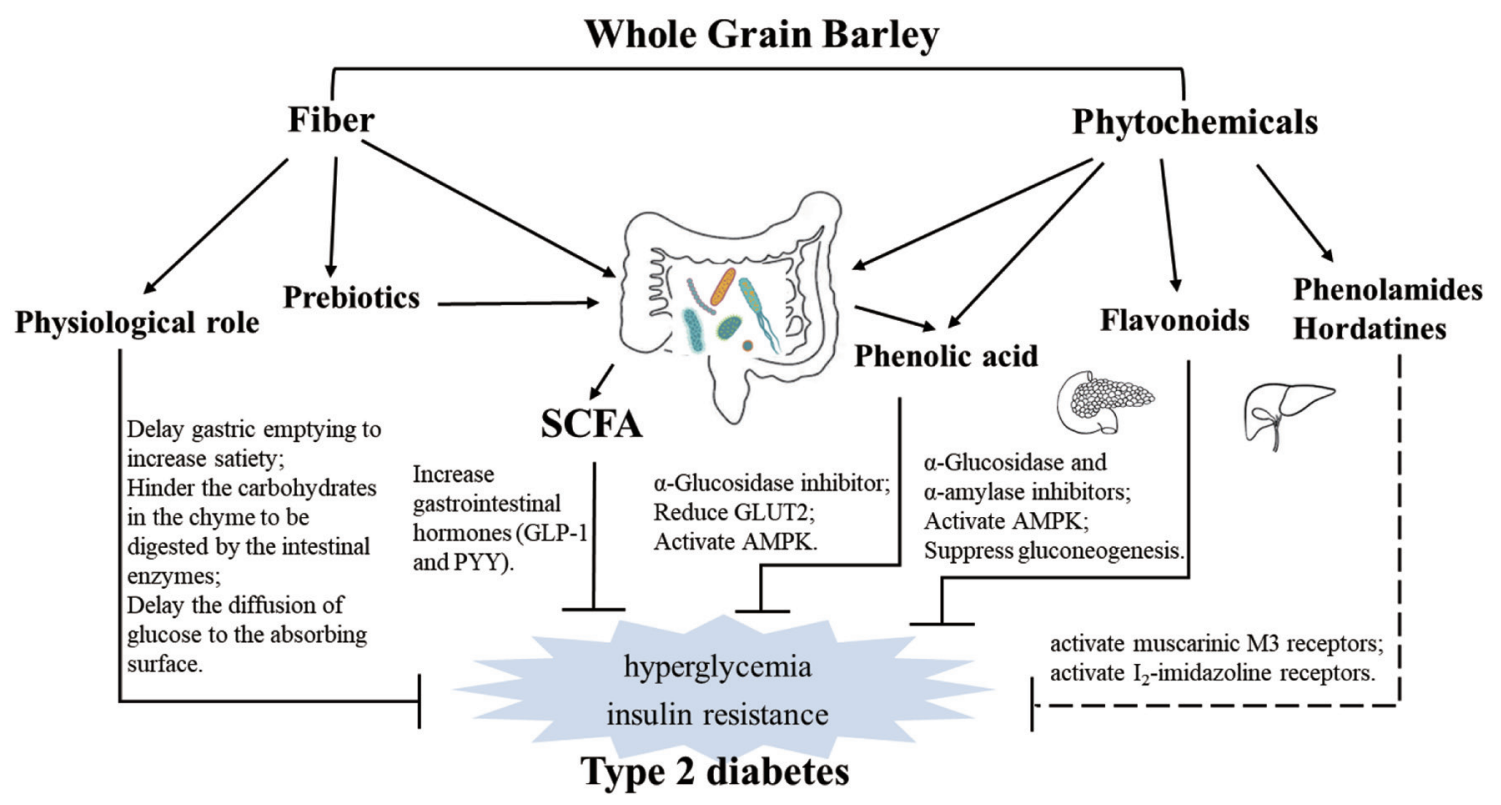

Figure 2. Overview of the effects of dietary fiber and phytochemicals in whole grain barley on type $\mathbf{2}$ diabetes with variety of mechanisms.

lowering glucose response when at least $4 \mathrm{~g}$ of $\beta$-glucans per $30 \mathrm{~g}$ of available carbohydrates are consumed in a meal (Henrion et al., 2019). One mechanism for this effect was related to the physical property of dietary fiber in barley, such as the viscosity. Multiple studies have shown a dose-response effect of $\beta$-glucans on the attenuation of postprandial glycemic response due to increased intestinal viscosity (Hassan 2016; Henrion et al., 2019). Particularly, the high water holding capacity and gelling property of $\beta$-glucans form a viscous solution, which causes a slower gastric emptying rate, which, in turn, delays the delivery of the chyme to the intestine. At the same time, the resistant to digestion character hinders the carbohydrates in the chyme to be digested by the intestinal enzyme and delays the diffusion of glucose to the absorbing surface (Henrion et al., 2019). Thondre et al. reported a decrease in glycemic response occasioned by increased viscosity and delayed gastric emptying after high molecular weight barley $\beta$-glucan intake, highlighting the role of viscosity in diabetes moderation (Thondre et al., 2013). Tosh et al. also proposed a mechanism for $\beta$-glucans ability to impact glycemic response centers around its viscosity and rheological behavior, which may slow down starch transport by decelerating $\alpha$-amylase diffusion towards its starch substrate. Additionally, a decrease in glucose absorption may arise from a reduction in the speed of sugars and $\alpha$-dextrins distribution towards the intestinal epithelium (Tosh and Bordenave 2020). $\beta$-glucan's resistant nature to digestion might also help explain its ability to improve postprandial blood glucose response.

While the larger concentration of fiber and $\beta$-glucan in barley compared to other cereal is thought to be the primary factor that influences its reported superior ability to favorably control diabetic risk factors, the structure and conformation of barley $\beta$-glucan may also play a role in its bioactivity. Besides, the rheological property of $\beta$-glucans play an important role in controlling blood glucose.

\subsection{Roles of microbial metabolites of fiber}

Barley may also affect diabetic risks by interacting with gut microbiota through the formation of microbial metabolites of fiber,
Short-chain fatty acids (SCFA), and acting as prebiotics (Figure 2).

SCFA are the primary bacterial metabolites of fiber. These metabolites have essential roles in metabolism, and their physiological relevance in diabetes moderation is receiving increased attention. High concentrations of SCFAs are assumed to be beneficial, as they can reduce hepatic glucose output and improve lipid homeostasis and may also influence the composition of the gut microbiota. SCFA such as acetate, propionate, and butyrate are also signal molecules that modulate glucose metabolism via distinct specific receptors. Through these receptors, such as the free fatty acid receptors, SCFA can increase the concentration of gastrointestinal hormones such as PYY and GLP-1 (Schloermann and Glei 2017). Both hormones play vital roles in altering diabetic risk factors as PYY induces glucose intake in muscle- and fat tissue, while GLP1 indirectly reduces blood glucose concentration by increasing the insulin concentration and reducing the production of glucagon in the pancreas. Also, obesity is associated with a pro-inflammatory state of the adipose tissue, which is connected with insulin resistance that causes T2D. SCFA such as propionate are capable of inducing the satiety hormone leptin. They can also reduce inflammatory cytokines and chemokines, indicating that SCFA has anti-inflammatory effects in human adipose tissue. A study by Roelofsen et al. found that WG products can offset any increase in glucose-induced TNF- $\alpha$ and IL- 6 . This ability to offset this increase was connected with an increase in plasma butyrate concentration, further suggesting that barley fiber can produce an SCFA profile that could proffer anti-inflammatory effect in diabetic cases (Roelofsen et al., 2010). Furthermore, concerning energy and glucose metabolism, SCFAs suppress appetite by increasing the release of satiety hormones and stimulating vagal afferent chemoreceptors. It can boost energy expenditure by upregulating thermogenesisrelated proteins in the liver and adipose tissue and also increase glucose-stimulated insulin secretion from pancreatic $\beta$-cells. Miyamoto et al.'s intervention study on glycemic response in diabetic mice found that $\beta$-glucan treatment improved glucose metabolism via SCFA. Increased levels of plasma PYY and GLP-1 were observed after barley flour diets, leading to the speculation that the suppression of food intake and improvement in insulin sensitivity 
induced by the barley flour diets was due to the promotion of gut hormone secretion from enteroendocrine cells by SCFAs, likely involving SCFA receptors GPR41 and GPR43 (Miyamoto et al., 2018). Studies have shown that butyric acid could improve insulin sensitivity via promotion of energy expenditure, regulation of histone deacetylases activity, and induction of mitochondria function (Gao et al., 2009; Khan and Jena 2016). Interestingly, in a study by Li et al. on T2D, it was observed that barley treatment increased the caecal levels of butyric acid together with improved insulin sensitivity (Li et al., 2020). Thus, indicating that increased insulin sensitivity by butyric acid signaling might be another mechanism by which barley ameliorates diabetic complications.

Barley dietary fiber can serve as prebiotics as they are converted to SCFAs by gut microbiota and can facilitate beneficial probiotics (Garcia-Mazcorro et al., 2018; Kovatcheva-Datchary et al., 2015; Sandberg et al., 2019). In a db/db mouse study, ${ }^{50}$ barley intake was reported to increase Prevotella and Lactobacillus' abundances while decreasing plasma insulin and resistin levels. In a human study exploring the modulatory impact of barley kernel-based bread on diabetes risk factors (Kovatcheva-Datchary et al., 2015), Petia Kovatcheva-Datchary and colleagues found that barley kernel-based bread acted as prebiotics by increasing Prevotella/Bacteroides ratio. The prebiotic action of the barley kernel-based bread ultimately induced improvements in glucose metabolism. In a metagenomic analysis where responders' gut microbiota was enriched with Prevotella copri and then transplanted to germ-free mice, germ-free mice exhibited improved glucose metabolism. This improvement was associated with an increased abundance of Prevotella and liver glycogen content compared to germ-free mice that received non-responder microbiota. Cristina Teixeira and colleagues (Teixeira et al., 2018) found that barley $\beta$-glucan increased the butyrate-producing bacteria, Lactobacillus, Blautia, and Allobaculum in rat models, thus indicating that barley $\beta$-glucan can improve glucose response via the production of butyrate.

\subsection{Role of phytochemicals}

Barley contains myriads of phytochemicals, including phenolic acid, flavonoids, phenolamides, and hordatines (Figure 3) (Ferreres et al., 2009; Holtekjølen et al., 2006; Idehen et al., 2017; Martínez et al., 2018; Pihlava 2014; Seikel and Bushnell 1959; Seikel and Geissman 1957). The most abundant phytochemicals in barley are phenolic acid, ferulic acid, and $p$-coumaric acid, mainly found in their bound forms. Some studies have shown that probiotic strains can free up these phenolic acids (Hole et al., 2012), and that bound phenolic acids are more effective than their free forms (Rondini et al., 2004). The bound ferulic acid content of different barley varieties has been reported to range between $403-723 \mathrm{mg} / \mathrm{kg}$, accounting for $52-69 \%$ of total phenolic acid in barley (Holtekjølen et al., 2006). $p$-Coumaric acid is the second most abundant phenolic acid in barley, with concentration ranging between 15-374 mg/ $\mathrm{kg}$ depending on barley variety. Deng and colleagues (Deng et al., 2020) quantified the phenolic profile of four highland barley varieties, discovering that aside from ferulic acid with $99.76-100 \%$ present in their bound form $(50.06-54.52 \mathrm{mg} / 100 \mathrm{~g}), 93.59-98.46 \%$ of naringin (bound form: $7.08-9.21 \mathrm{mg} / 100 \mathrm{~g}$ ), $0-52.65 \%$ of catechin (bound form: $0-2.11 \mathrm{mg} / 100 \mathrm{~g}$ ) and $100 \%$ of quercetin (bound form: 1.4-3.0 mg/100 g) also existed in barley in bound forms. The correct proportions of these essential bioactive compounds are easily underestimated when considering their importance in health promotion. In diabetic moderation, phenolic acids, catechin, and quercetin have been found to exert $\alpha$-glucosidase and $\alpha$-amylase inhibitory effect (Figure 2) (Adisakwattana et al., 2004; Gong et al., 2020; Rasouli et al., 2017; Tadera et al., 2006; Xiao et al., 2013), consequently leading to the belief that barley phytochemicals modulate the effect of carbohydrates and blood sugar levels, thereby preventing hyperglycemia. Naringin was reported to possess a potent anti-hyperglycemic impact in a study involving NA/STZ-induced type 2 diabetic rats (Ahmed et al., 2017). The antidiabetic effect of ferulic and $p$-coumaric acids have also been studied in several animal studies (Abdel-Moneim et al., 2018; Amalan et al., 2016; Amalan et al., 2015; Narasimhan et al., 2015; Narasimhan et al., 2015). In a high fat and fructose-induced T2D rat study, Akilavalli Narasimhan and colleagues found that ferulic acid reduces hepatic glucose production by preventing the interaction between FoxO1 and the genes involved in gluconeogenesis. In the same study, it was found that ferulic acid reduced hepatic GLUT2 expression through the interaction between transcription factors of SREBP1c, HNF1, HNF3, and GLUT2 gene promoter (Narasimhan et al., 2015). $p$-Coumaric acid has also been reported to present a similar effect. In an STZ induced diabetic rat study, Venkatesan Amalan and colleagues demonstrated that $p$-coumaric acid could increase the plasma insulin levels and decrease the expression of GLUT 2 mRNA in the pancreas. This $p$-coumaric acid benefits significantly lowered blood glucose, glucose-6-phosphatase, fructose-1, and 6-bisphosphatase levels, while increasing the levels of hexokinase and glucose- 6 phosphatase dehydrogenase (Amalan et al., 2016; Amalan et al., 2015). In a similar study involving rat models induced for T2D with NA/STZ, Adel AbdelMoneim and colleagues found that $p$-coumaric acid decreased TNF- $\alpha$ and adipocytokines secretion while upregulating PPAR $\gamma$ mRNA expression, thereby exhibiting antidiabetic effect (AbdelMoneim et al., 2018). Moreover, in a muscle cell model study, Seon-A Yoon and colleagues demonstrated that $p$-coumaric acid could modulate glucose response through AMP-activated protein kinase (Yoon et al., 2013).

Another important kind of phytochemicals in barley with possible antidiabetic effects are the agmatine conjugated phenolamides and their dimers hordatines. Among these phytochemicals, hordatines are unique to barley, with their total level and bioactivity still unclear (Pihlava 2014). In 2013, Kohyama N and Ono H (Kohyama and Ono 2013) purified Hordatine A $\beta$-D-glucopyranoside from ungerminated barley grains and quantified its contents, which ranged from 103-254 nmol/g dry weight in ten cultivars of ungerminated mature grains, equal to $7.3-18.1 \mathrm{mg} / 100 \mathrm{~g}$ dry weight. Hordatines contain a guanidine group from their elucidated structures, which is similar to the antidiabetic drug metformin. Also, hordatine A can bind to the muscarinic M3 receptors, which are critical regulators of glucose homeostasis (Gautam et al., 2006). Besides, agmatine was reported to activate the $\mathrm{I}_{2}$-imidazoline receptors, thereby improving insulin sensitivity and increasing $\beta$-endorphin secretion in type-2 diabetic rats model (Chang et al., 2010; Su et al., 2009). These findings strongly indicate that agmatine conjugated phenolamides and hordatines are potential antidiabetic phytochemicals and can also contribute to the antidiabetic effect of barley.

Federico and colleagues (Ferreres et al., 2009) identified and quantified 28 phenolic compounds in barley leaves, seeds, awns, and stems. The total amount of these compounds in seeds was 50.0 $\mathrm{mg} / \mathrm{kg}$, including lutonarin $(1.5 \mathrm{mg} / \mathrm{kg})$ and saponarin $(2.0 \mathrm{mg} / \mathrm{kg})$, which were also present in barley leaves at $2,150.8$ and $145.3 \mathrm{mg} /$ $\mathrm{kg}$ concentrations, respectively. Saponarin are $\alpha$-glucosidase inhibitor (Sengupta et al., 2009), and their presence in barley seeds and leaves portend well for their use as antidiabetic agents. WooDuck Seo and colleagues (Seo et al., 2015) found that the administration of barley sprout extract for 12 weeks lowered fasting glu- 
(1) Phenolic acids<smiles>O=C(O)/C=C/c1ccc(O)cc1</smiles>

p-coumaric acid<smiles>COc1cc(/C=C/C(=O)O)ccc1O</smiles>

ferulic acid

\section{(2) Flavonoids}<smiles>Oc1cc(O)c2c(c1)O[C@H](c1ccc(O)c(O)c1)[C@H](O)C2</smiles>

catechin<smiles>O=c1c(O)c(-c2ccc(O)c(O)c2)oc2cc(O)cc(O)c12</smiles>

quercetin<smiles>CC1OC(OC2OC(Oc3cc(O)c4c(c3)OC(c3ccc(O)cc3)CC4=O)C(OC3C(O)C(O)C(O)C3O)C(O)C2O)C(O)C1O</smiles>

naringin<smiles></smiles><smiles>O=c1cc(-c2ccc(O)cc2)oc2cc(OC3OC(CO)(CO)C(O)C(O)C3O)c(C(OC(O)C(O)C(O)CO)C(O)CO)c(O)c12</smiles>

\section{(3) Phenolamides and hordatines}<smiles>NC(=O)NCCCCCNC(=O)/C=C/c1ccc(O)cc1</smiles><smiles>N=C(N)CCCCCNC(=O)/C=C/c1ccc2c(c1)C(C(=O)NCCCCNC(=N)N)C(c1ccc(O)cc1)O2</smiles>

hordatine A<smiles>COc1cc(/C=C/C(=O)NCCCCNC(=N)N)ccc1O</smiles>

feruloyl agmatine<smiles>COc1ccc(C2Oc3ccc(/C=C/C(=O)NCCCCNC(=N)N)cc3C2C(=O)NCCCCNC(=N)N)cc1</smiles>

hordatine A $\beta$-D-glucopyranoside

Figure 3. The structures of phenolic acids, flavonoids, phenolamides, and hordatines in barley.

cose levels in the plasma and improved insulin sensitivity in mice fed a high-fat diet. In that same study, the molecular mechanism of saponarin for regulating insulin sensitivity was investigated. Additionally, saponarin in barley can suppress the rate of gluconeogenesis and increase cellular glucose uptake in HepG2 and TE671 cells by activating AMPK in a calcium-dependent manner. Thus, barley flavonoids might also contribute to barley's antidiabetic effect with its benefits obtained through the consumption of barley malts or barley grass.

\section{Conclusion}

Barley is a high-fiber, low-fat WG with a low-energy-density that aligns with recommendations for a low-calorie, high-fiber diet for glycemic control. The mechanism by which barley reduces postprandial glucose levels is thought to be mainly by increasing the intestinal contents' viscosity, which reduces carbohydrate digestion and absorption. The viscosity of barley and barley $\beta$-glucan is determined by its molecular weight and the amount solubilized in the intestine. From a structure point, barley $\beta$-glucan is a linear chain polysaccharide made of units of $\beta$-D-glucopyranosyl residues linked by 1,3 and 1,4 glycosidic bonds. The $\beta-1,3$ linkage breaks up the uniform structure, allowing it to form viscous solutions upon solubilization. The rheology and structure of $\beta$-glucan through several mechanisms play an essential role in reducing postprandial blood glucose via fermentability and creating high viscosity solutions in humans to delay gastric emptying. Different mechanisms that would explain barley's glucose and insulin lowering effects have been suggested. Significant considerations focus on the formation of SCFA in the colon and the interaction between barley $\beta$-glucan and gut microbiota by playing as the prebiotics. Additionally, barley's phytochemicals also play a role in maintaining a healthy gut microbiota that can alter postprandial glucose response. However, the interplay between fiber, microbiota, and phytochemicals in diabetes moderation still needs to be thoroughly investigated and understood. A well-designed human study investigating the long-term benefits of barley and barley $\beta$-glucan con- 
sumption among individuals with diabetics is also highly required.

\section{References}

Abdel-Moneim, A., Abd El-Twab, S.M., Yousef, A.I., Reheim, E.S.A., and Ashour, M.B. (2018). Modulation of hyperglycemia and dyslipidemia in experimental type 2 diabetes by gallic acid and p-coumaric acid: The role of adipocytokines and PPARY. Biomed. Pharmacother. 105: 1091-1097.

AbuMweis, S., Thandapilly, S.J., Storsley, J., and Ames, N. (2016). Effect of barley $\beta$-glucan on postprandial glycaemic response in the healthy human population: A meta-analysis of randomized controlled trials. J. Funct. Foods. 27: 329-342.

Adisakwattana, S., Sookkongwaree, K., Roengsumran, S., Petsom, A., Ngamrojnavanich, N., Chavasiri, W., Deesamer, S., and Yibchok-anun, S. (2004). Structure-activity relationships of trans-cinnamic acid derivatives on $\alpha$-glucosidase inhibition. Bioorg. Med. Chem. Lett. 14(11): 2893-2896.

Ahmed, O.M., Hassan, M.A., Abdel-Twab, S.M., and Azeem, M.N.A. (2017). Navel orange peel hydroethanolic extract, naringin and naringenin have anti-diabetic potentials in type 2 diabetic rats. Biomed. Pharmacother. 94: 197-205.

Aldughpassi, A., Abdel-Aal, el-S.M., and Wolever, T.M. (2012). Barley cultivar, kernel composition, and processing affect the glycemic index. J. Nutr. 142(9): 1666-1671.

Amalan, V., Vijayakumar, N., Indumathi, D., and Ramakrishnan, A. (2016). Antidiabetic and antihyperlipidemic activity of $p$-coumaric acid in diabetic rats, role of pancreatic GLUT 2: In vivo approach. Biomed. Pharmacother. 84: 230-236.

Amalan, V., Vijayakumar, N., and Ramakrishnan, A. (2015). p-Coumaric acid regulates blood glucose and antioxidant levels in streptozotocin induced diabetic rats. J. Chem. Pharm. Res. 7: 831-839.

Ames, N., Blewett, H., Storsley, J., Thandapilly, S.J., Zahradka, P., and Taylor, C. (2015). A double-blind randomised controlled trial testing the effect of a barley product containing varying amounts and types of fibre on the postprandial glucose response of healthy volunteers. $\mathrm{Br}$. J. Nutr. 113(9): 1373-1383.

American Diabetes Association. (2017). 5. Prevention or delay of type 2 diabetes. Diabetes Care. 40(Supplement 1): S44-\$47.

Atkinson, F.S., Foster-Powell, K., and Brand-Miller, J.C. (2008). International tables of glycemic index and glycemic load values: 2008. Diabetes Care. 31(12): 2281-2283.

Aydin, Ö., Nieuwdorp, M., and Gerdes, V. (2018). The gut microbiome as a target for the treatment of type 2 diabetes. Curr. Diabetes Rep. 18(8): 55.

Azam, A., Itrat, N., and Ahmed, U. (2019). Hypoglycemic Effect of Barley (Hordeum vulgare) in Diabetics. IJISRT. 4(5): 515-519.

Bai, J., Ren, Y., Li, Y., Fan, M., Qian, H., Wang, L., Wu, G., Zhang, H., Qi, X., and $\mathrm{Xu}, \mathrm{M}$. (2019). Physiological functionalities and mechanisms of $\beta$-glucans. Trends Food Sci. Technol. 88: 57-66.

Behall, K.M., Scholfield, D.J., and Hallfrisch, J. (2005). Comparison of hormone and glucose responses of overweight women to barley and oats. J. Am. Coll. Nutr. 24(3): 182-188.

Behall, K.M., Scholfield, D.J., and Hallfrisch, J.G. (2006). Barley $\beta$-glucan reduces plasma glucose and insulin responses compared with resistant starch in men. Nutr. Res. 26(12): 644-650.

Belobrajdic, D.P., and Bird, A.R. (2013). The potential role of phytochemicals in wholegrain cereals for the prevention of type-2 diabetes. Nutr. J. 12(1): 62 .

Belobrajdic, D.P., Jobling, S.A., Morell, M.K., Taketa, S., and Bird, A.R. (2015). Wholegrain barley $\beta$-glucan fermentation does not improve glucose tolerance in rats fed a high-fat diet. Nutr. Res. 35(2): 162168.

Bourdon, I., Yokoyama, W., Davis, P., Hudson, C., Backus, R., Richter, D., Knuckles, B., and Schneeman, B.O. (1999). Postprandial lipid, glucose, insulin, and cholecystokinin responses in men fed barley pasta enriched with $\beta$-glucan. Am. J. Clin. Nutr. 69(1): 55-63.

Bozbulut, R., and Sanlier, N. (2019). Promising effects of $\beta$-glucans on glyceamic control in diabetes. Trends Food Sci. Technol. 83: 159-166.
Brennan, C.S. (2005). Dietary fibre, glycaemic response, and diabetes. Mol. Nutr. Food Res. 49(6): 560-570.

Brockman, D.A., Chen, X., and Gallaher, D.D. (2013). Consumption of a high $\beta$-glucan barley flour improves glucose control and fatty liver and increases muscle acylcarnitines in the Zucker diabetic fatty rat. Eur. J. Nutr. 52(7): 1743-1753.

Bullard, K.M., Cowie, C.C., Lessem, S.E., Saydah, S.H., Menke, A., Geiss, L.S., Orchard, T.J., Rolka, D.B., and Imperatore, G. (2018). Prevalence of diagnosed diabetes in adults by diabetes type-United States, 2016. MMWR. 67(12): 359.

Casiraghi, M.C., Garsetti, M., Testolin, G., and Brighenti, F. (2006). Postprandial responses to cereal products enriched with barley $\beta$-glucan. J. Am. Coll. Nutr. 25(4): 313-320.

Centers for Disease Control and Prevention. (2020). National diabetes statistics report, 2020. Atlanta, GA: Centers for Disease Control and Prevention, US Department of Health and Human Services. https:// www.cdc.gov/diabetes/data/statistics-report/index.html.

Chang, C.H., Wu, H.T., Cheng, K.C., Lin, H.J., and Cheng, J.T. (2010). Increase of $\beta$-endorphin secretion by agmatine is induced by activation of imidazoline I2A receptors in adrenal gland of rats. Neurosci. Lett. 468(3): 297-299.

Chillo, S., Ranawana, D.V., Pratt, M., and Henry, C.J.K. (2011). Glycemic response and glycemic index of semolina spaghetti enriched with barley $\beta$-glucan. Nutrition. 27(6): 653-658.

Choi, J.S., Kim, H., Jung, M.H., Hong, S., and Song, J. (2010). Consumption of barley $\beta$-glucan ameliorates fatty liver and insulin resistance in mice fed a high-fat diet. Mol. Nutr. Food Res. 54(7): 1004-1013.

Critchley, J.A., Carey, I.M., Harris, T., DeWilde, S., Hosking, F.J., and Cook, D.G. (2018). Glycemic control and risk of infections among people with type 1 or type 2 diabetes in a large primary care cohort study. Diabetes Care. 41(10): 2127-2135.

Croke, L.M. (2016). DGAC Makes Food-Based Recommendations in the 2015-2020 Dietary Guidelines for Americans. Am. Fam. Physician. 93(6): 525-525.

Della Pepa, G., Vetrani, C., Vitale, M., and Riccardi, G. (2018). Wholegrain intake and risk of type 2 diabetes: evidence from epidemiological and intervention studies. Nutrients. 10(9): 1288.

Deng, N., Zheng, B., Li, T., and Liu, R.H. (2020). Assessment of the Phenolic Profiles, Hypoglycemic Activity, and Molecular Mechanism of Different Highland Barley (Hordeum vulgare L.) Varieties. Int. J. Mol. Sci. 21(4): 1175.

DeSalvo, K.B. (2016). Public Health 3.0: applying the 2015-2020 Dietary Guidelines for Americans. Public Health Rep. 131(4): 518-521.

Eleazu, C.O. (2016). The concept of low glycemic index and glycemic load foods as panacea for type 2 diabetes mellitus; prospects, challenges and solutions. Afr. Health Sci. 16(2): 468-479.

Esposito, S., Toni, G., Tascini, G., Santi, E., Berioli, M.G., and Principi, N. (2019). Environmental factors associated with type 1 diabetes. Front. Endocrinol. 10: 592.

Evert, A.B., Dennison, M., Gardner, C.D., Garvey, W.T., Lau, K.H.K., MacLeod, J., Mitri, J., Pereira, R.F., Rawlings, K., and Robinson, S. (2019). Nutrition therapy for adults with diabetes or prediabetes: a consensus report. Diabetes Care. 42(5): 731-754.

Ferreres, F., Kršková, Z., Gonçalves, R.F., Valentão, P.C., Pereira, J.A., Dušek, J., Martin, J., and Andrade, P.B. (2009). Free water-soluble phenolics profiling in barley (Hordeum vulgare L.). J. Agric. Food Chem. 57(6): 2405-2409.

Fujiwara, N., Hall, C., and Jenkins, A.L. (2017). Development of low glycemic index (GI) foods by incorporating pulse ingredients into cerealbased products: Use of in vitro screening and in vivo methodologies. Cereal Chem. 94(1): 110-116.

Gæde, P., Oellgaard, J., Carstensen, B., Rossing, P., Lund-Andersen, H., Parving, H.-H., and Pedersen, O. (2016). Years of life gained by multifactorial intervention in patients with type 2 diabetes mellitus and microalbuminuria: 21 years follow-up on the Steno- 2 randomised trial. Diabetologia. 59(11): 2298-2307.

Gao, Z., Yin, J., Zhang, J., Ward, R.E., Martin, R.J., Lefevre, M., Cefalu, W.T., and Ye, J. (2009). Butyrate improves insulin sensitivity and increases energy expenditure in mice. Diabetes. 58(7): 1509-1517.

Garcia-Mazcorro, J.F., Mills, D.A., Murphy, K., and Noratto, G. (2018). Effect of barley supplementation on the fecal microbiota, caecal biochemis- 
try, and key biomarkers of obesity and inflammation in obese $\mathrm{db} / \mathrm{db}$ mice. Eur. J. Nutr. 57(7): 2513-2528.

Gautam, D., Han, S.-J., Hamdan, F.F., Jeon, J., Li, B., Li, J.H., Cui, Y., Mears, D., Lu, H., and Deng, C. (2006). A critical role for $\beta$ cell M3 muscarinic acetylcholine receptors in regulating insulin release and blood glucose homeostasis in vivo. Cell Metab. 3(6): 449-461.

Gong, L., Feng, D., Wang, T., Ren, Y., Liu, Y., and Wang, J. (2020). Inhibitors of $\alpha$-amylase and $\alpha$-glucosidase: Potential linkage for whole cereal foods on prevention of hyperglycemia. Food Sci. Nutr. 8(12): 6320-6337.

Goudar, G., Sharma, P., Janghu, S., and Longvah, T. (2020). Effect of processing on barley $\beta$-glucan content, its molecular weight and extractability. Int. J. Biol. Macromol. 162: 1204-1216.

Hassan, D.R. (2016). Effects of oat and barley on some biochemical parameters in hyperglycemic rats and their effects on properties of dough and baked bread. J. Stud. Srch. Specif. Educ. 2(1): 201-218.

Henrion, M., Francey, C., Lê, K.-A., and Lamothe, L. (2019). Cereal $\beta$-glucans: the impact of processing and how it affects physiological responses. Nutrients. 11(8): 1729

Higa, M., Fuse, Y., Miyashita, N., Fujitani, A., Yamashita, K., Ichijo, T., Aoe, S., and Hirose, T. (2019). Effect of high $\beta$-glucan barley on postprandial blood glucose levels in subjects with normal glucose tolerance: assessment by meal tolerance test and continuous glucose monitoring system. Clin. Nutr. Res. 8(1): 55-63.

Hinata, M., Ono, M., Midorikawa, S., and Nakanishi, K. (2007). Metabolic improvement of male prisoners with type 2 diabetes in Fukushima Prison, Japan. Diabetes Res. Clin. Pract. 77(2): 327-332.

Hole, A.S., Rud, I., Grimmer, S., Sigl, S., Narvhus, J., and Sahlstrøm, S. (2012). Improved bioavailability of dietary phenolic acids in whole grain barley and oat groat following fermentation with probiotic Lactobacillus acidophilus, Lactobacillus johnsonii, and Lactobacillus reuteri. J. Agric. Food Chem. 60(25): 6369-6375.

Holman, N., Young, B., and Gadsby, R. (2015). Current prevalence of Type 1 and Type 2 diabetes in adults and children in the UK. Diabet. Med. 32(9): 1119.

Holtekjølen, A.K., Kinitz, C., and Knutsen, S.H. (2006). Flavanol and bound phenolic acid contents in different barley varieties. J. Agric. Food Chem. 54(6): 2253-2260.

Hong, H., and Jai Maeng, W. (2004). Effects of malted barley extract and banaba extract on blood glucose levels in genetically diabetic mice. J. Med. Food. 7(4): 487-490.

Idehen, E., Tang, Y., and Sang, S. (2017). Bioactive phytochemicals in barley. J. Food Drug Anal. 25(1): 148-161.

Kavitha, G., and Parameshwari, S. (2019). Development and standardization of low glycemic index foods for type 2 diabetic patients. IJASRM. 4(5): 114-121.

Khan, S., and Jena, G. (2016). Sodium butyrate reduces insulin-resistance, fat accumulation and dyslipidemia in type-2 diabetic rat: a comparative study with metformin. Chem.-Biol. Interact. 254: 124-134

Kim, C.H. (2018). Microbiota or short-chain fatty acids: which regulates diabetes? Cell. Mol. Immunol. 15(2): 88-91.

Kim, Y., Keogh, J.B., and Clifton, P.M. (2017). Effects of two different dietary patterns on inflammatory markers, advanced glycation end products and lipids in subjects without type 2 diabetes: a randomised crossover study. Nutrients. 9(4): 336.

Kohyama, N., and Ono, H. (2013). Hordatine A $\beta$-D-glucopyranoside from ungerminated barley grains. J. Agric. Food Chem. 61(5): 1112-1116.

Kovatcheva-Datchary, P., Nilsson, A., Akrami, R., Lee, Y.S., De Vadder, F., Arora, T., Hallen, A., Martens, E., Björck, I., and Bäckhed, F. (2015) Dietary fiber-induced improvement in glucose metabolism is associated with increased abundance of Prevotella. Cell Metab. 22(6): 971-982.

Lazaridou, A., and Biliaderis, C. (2004). Cryogelation of cereal $\beta$-glucans: structure and molecular size effects. Food Hydrocolloids. 18(6): 933-947.

Lazaridou, A., Biliaderis, C., Micha-Screttas, M., and Steele, B.R. (2004). A comparative study on structure-function relations of mixed-linkage $(1 \rightarrow 3)$, $(1 \rightarrow 4)$ linear $\beta$-d-glucans. Food Hydrocolloids. 18(5): 837855

Lee, C.J., Horsley, R., Manthey, F., and Schwarz, P. (1997). Comparisons of $\beta$-glucan content of barley and oat. Cereal Chem. 74(5): 571-575.
Li, L., Pan, M., Pan, S., Li, W., Zhong, Y., Hu, J., and Nie, S. (2020). Effects of insoluble and soluble fibers isolated from barley on blood glucose, serum lipids, liver function and caecal short-chain fatty acids in type 2 diabetic and normal rats. Food Chem. Toxicol. 135: 110937.

Li, Z., Ye, C.y., Zhao, T.Y., and Yang, L. (2020). Model of genetic and environmental factors associated with type 2 diabetes mellitus in a Chinese Han population. BMC public health. 20(1): 1-12.

Liljeberg, H.G., Åkerberg, A.K., and Björck, I.M. (1999). Effect of the glycemic index and content of indigestible carbohydrates of cereal-based breakfast meals on glucose tolerance at lunch in healthy subjects. Am. J. Clin. Nutr. 69(4): 647-655.

Liu, L., Wang, X., Li, Y., and Sun, C. (2015). Postprandial differences in the amino acid and biogenic amines profiles of impaired fasting glucose individuals after intake of highland barley. Nutrients. 7(7): 55565571

Malin, S.K., Kullman, E.L., Scelsi, A.R., Haus, J.M., Filion, J., Pagadala, M.R., Godin, J.-P., Kochhar, S., Ross, A.B., and Kirwan, J.P. (2018). A wholegrain diet reduces peripheral insulin resistance and improves glucose kinetics in obese adults: A randomized-controlled trial. Metab. Clin. Exp. 82: 111-117

Martínez, M., Motilva, M.-J., de las Hazas, M.-C.L., Romero, M.-P., Vaculova, K., and Ludwig, I.A. (2018). Phytochemical composition and $\beta$-glucan content of barley genotypes from two different geographic origins for human health food production. Food Chem. 245: 61-70.

Mikkelsen, M.S., Jespersen, B.M., Larsen, F.H., Blennow, A., and Engelsen, S.B. (2013). Molecular structure of large-scale extracted $\beta$-glucan from barley and oat: Identification of a significantly changed block struc ture in a high $\beta$-glucan barley mutant. Food Chem. 136(1): 130-138.

Miyamoto, J., Watanabe, K., Taira, S., Kasubuchi, M., Li, X., Irie, J., Itoh, H. and Kimura, I. (2018). Barley $\beta$-glucan improves metabolic condition via short-chain fatty acids produced by gut microbial fermentation in high fat diet fed mice. PLoS One. 13(4): e0196579.

Narasimhan, A., Chinnaiyan, M., and Karundevi, B. (2015). Ferulic acid exerts its antidiabetic effect by modulating insulin-signalling molecules in the liver of high-fat diet and fructose-induced type-2 diabetic adult male rat. Appl. Physiol., Nutr., Metab. 40(8): 769-781.

Narasimhan, A., Chinnaiyan, M., and Karundevi, B. (2015). Ferulic acid regulates hepatic GLUT2 gene expression in high fat and fructoseinduced type-2 diabetic adult male rat. Eur. J. Pharmacol. 761: 391397.

Nilsson, A.C., OÖstman, E.M., Granfeldt, Y., and Björck, I.M. (2008). Effect of cereal test breakfasts differing in glycemic index and content of indigestible carbohydrates on daylong glucose tolerance in healthy subjects. Am. J. Clin. Nutr. 87(3): 645-654.

Pick, M., Hawrysh, Z.J., Gee, M., and Toth, E. (1998). Barley bread products improve glycemic control of type 2 subjects. Int. J. Food Sci. Nutr. 49(1): 71-78

Pihlava, J.M. (2014). Identification of hordatines and other phenolamides in barley (Hordeum vulgare) and beer by UPLC-QTOF-MS. J. Cerea Sci. 60(3): 645-652.

Rasouli, H., Hosseini-Ghazvini, S.M.-B., Adibi, H., and Khodarahmi, R. (2017). Differential $\alpha$-amylase/ $\alpha$-glucosidase inhibitory activities of plant-derived phenolic compounds: a virtual screening perspective for the treatment of obesity and diabetes. Food Funct. 8(5): 19421954.

Redondo, M.J., Hagopian, W.A., Oram, R., Steck, A.K., Vehik, K., Weedon, M., Balasubramanyam, A., and Dabelea, D. (2020). The clinical consequences of heterogeneity within and between different diabetes types. Diabetologia. 63(10): 2040-2048.

Rendell, M., Vanderhoof, J., Venn, M., Shehan, M., Arndt, E., Rao, C., Gill, G., Newman, R., and Newman, C. (2005). Effect of a barley breakfast cereal on blood glucose and insulin response in normal and diabetic patients. Plant Foods Hum. Nutr. 60(2): 63-67.

Roelofsen, H., Priebe, M., and Vonk, R. (2010). The interaction of shortchain fatty acids with adipose tissue: relevance for prevention of type 2 diabetes. Benefic. Microbes. 1(4): 433-437.

Rondini, L., Peyrat-Maillard, M.-N., Marsset-Baglieri, A., Fromentin, G. Durand, P., Tomé, D., Prost, M., and Berset, C. (2004). Bound ferulic acid from bran is more bioavailable than the free compound in rat. J. Agric. Food Chem. 52(13): 4338-4343.

Sado, J., Kitamura, T., Noma, N., Saito, M., Azuma, H., Azuma, T., Sobue, T. 
and Kitamura, Y. (2016). Socio-environmental factors associated with diabetes mellitus among patients hospitalized with schizophrenia in Japan. Environ. Health Prev. Med. 21(6): 460-469.

Sandberg, J., Kovatcheva-Datchary, P., Björck, I., Bäckhed, F., and Nilsson, A. (2019). Abundance of gut Prevotella at baseline and metabolic response to barley prebiotics. Eur. J. Nutr. 58(6): 2365-2376.

Schloermann, W., and Glei, M. (2017). Potential health benefits of $\beta$-glucan from barley and oat. Ernahrungs Umschau. 64(10): 145-149.

Schroeder, N., Gallaher, D.D., Arndt, E.A., and Marquart, L. (2009). Influence of whole grain barley, whole grain wheat, and refined ricebased foods on short-term satiety and energy intake. Appetite. 53(3): 363-369.

Seikel, M.K., and Bushnell, A.J. (1959). The Flavonoid Constituents of Barley (Hordeum vulgare). II. Lutonarin1. J. Org. Chem. 24(12): 19951997.

Seikel, M.K., and Geissman, T. (1957). The flavonoid constituents of barley (Hordeum vulgare). I. Saponarin. Arch. Biochem. Biophys. 71(1): 17-30.

Sengupta, S., Mukherjee, A., Goswami, R., and Basu, S. (2009). Hypoglycemic activity of the antioxidant saponarin, characterized as $\alpha$-glucosidase inhibitor present in Tinospora cordifolia. J. Enzyme Inhib. Med. Chem. 24(3): 684-690.

Seo, W.D., Lee, J.H., Jia, Y., Wu, C., and Lee, S.J. (2015). Saponarin activates AMPK in a calcium-dependent manner and suppresses gluconeogenesis and increases glucose uptake via phosphorylation of CRTC2 and HDAC5. Bioorg. Med. Chem. Lett. 25(22): 5237-5242.

Shatwan, I.A., Ahmed, L.A., and Badkook, M.M. (2013). Effect of barley flour, crude cinnamon, and their combination on glycemia, dyslipidemia, and adipose tissue hormones in type 2 diabetic rats. J. Med. Food. 16(7): 656-662.

Smith, K.N., Queenan, K.M., Thomas, W., Fulcher, R.G., and Slavin, J.L. (2008). Physiological effects of concentrated barley $\beta$-glucan in mildly hypercholesterolemic adults. J. Am. Coll. Nutr. 27(3): 434-440.

Su, C.H., Liu, I.M., Chung, H.H., and Cheng, J.T. (2009). Activation of I2-imidazoline receptors by agmatine improved insulin sensitivity through two mechanisms in type-2 diabetic rats. Neurosci. Lett. 457(3): 125128.

Tadera, K., Minami, Y., Takamatsu, K., and Matsuoka, T. (2006). Inhibition of $\alpha$-glucosidase and $\alpha$-amylase by flavonoids. J. Nutr. Sci. Vitaminol. 52(2): 149-153.
Teixeira, C., Prykhodko, O., Alminger, M., Fåk Hållenius, F., and Nyman, M. (2018). Barley products of different fiber composition selectively change microbiota composition in rats. Mol. Nutr. Food Res. 62(19): 1701023.

Thondre, P., Shafat, A., and Clegg, M. (2013). Molecular weight of barley $\beta$-glucan influences energy expenditure, gastric emptying and glycaemic response in human subjects. Br. J. Nutr. 110(12): 2173-2179.

Thondre, P.S., and Henry, C.J.K. (2011). Effect of a low molecular weight high-purity $\beta$-glucan on in vitro digestion and glycemic response. Int. J. Food Sci. Nutr. 62(7): 678-684.

Thondre, P.S., Wang, K., Rosenthal, A.J., and Henry, C.J. (2012). Glycaemic response to barley porridge varying in dietary fibre content. $\mathrm{Br}$. J. Nutr. 107(5): 719-724.

Tosh, S. (2013). Review of human studies investigating the post-prandial blood-glucose lowering ability of oat and barley food products. Eur. J. Clin. Nutr. 67(4): 310-317.

Tosh, S.M., and Bordenave, N. (2020). Emerging science on benefits of whole grain oat and barley and their soluble dietary fibers for heart health, glycemic response, and gut microbiota. Nutr. Rev. 78(Supplement_1): 13-20.

Vaikousi, H., Biliaderis, C., and Izydorczyk, M. (2004). Solution flow behavior and gelling properties of water-soluble barley $(1 \rightarrow 3,1 \rightarrow 4)$ - $\beta$-glucans varying in molecular size. J. Cereal Sci. 39(1): 119-137.

Weickert, M.O., and Pfeiffer, A.F. (2018). Impact of dietary fiber consumption on insulin resistance and the prevention of type 2 diabetes. J. Nutr. 148(1): 7-12.

Wolever, T.M. The glycaemic index: a physiological classification of dietary carbohydrate, $\mathrm{CABI}$.

Wood, P.J. (2011). Oat $\beta$-glucan: properties and function. Oats: Chem. Technol. (Ed. 2). pp. 219-254.

Woodward, J., Fincher, G., and Stone, B. (1983). Water-soluble $(1 \rightarrow 3)$, $(1 \rightarrow 4)-\beta$-D-glucans from barley (Hordeum vulgare) endosperm. II. Fine structure. Carbohydr. Polym. 3(3): 207-225.

Xiao, J., Ni, X., Kai, G., and Chen, X. (2013). A review on structure-activity relationship of dietary polyphenols inhibiting $\alpha$-amylase. Crit. Rev. Food Sci. Nutr. 53(5): 497-506.

Yoon, S.A., Kang, S.I., Shin, H.S., Kang, S.W., Kim, J.H., Ko, H.C., and Kim, S.J. (2013). p-Coumaric acid modulates glucose and lipid metabolism via AMP-activated protein kinase in L6 skeletal muscle cells. Biochem. Biophys. Res. Commun. 432(4): 553-557. 